\title{
The Association Between Helicobacter Pylori and Perforated Gastroduodenal Ulcer
}

Katavath Thirupathaiah ${ }^{1}$, Loganathan Jayapal ${ }^{2,1}$, Anandhi Amaranathan ${ }^{1}$, Chellappa Vijayakumar ${ }^{1}$, Mangala Goneppanavar ${ }^{3}$, Vishnu Prasad Nelamangala Ramakrishnaiah ${ }^{1}$

1. Surgery, Jawaharlal Institute of Postgraduate Medical Education and Research (JIPMER), Puducherry, IND 2. Surgery, Lala Lajpat Rai Memorial Medical College, Meerut, IND 3. Pathology, Mahatma Gandhi Medical College and Research Institute, Puducherry, IND

Corresponding author: Vishnu Prasad Nelamangala Ramakrishnaiah,vprasad285@gmail.com

\section{Abstract \\ Background}

Although the role of Helicobacter pylori (H. pylori) is well known in peptic ulcer disease (PUD) etiology, its role in perforated peptic ulcer (PPU) is not well established. This study aimed to assess the role of H. pylori infection in patients with PPU and to compare it with its prevalence in patients with PUD.

\section{Methodology}

This prospective analytical study was conducted for two years. The study patients were classified into two groups: group I consisted of patients $(n=48)$ operated for PPU and group II were patients $(n=48)$ with PUD diagnosed by endoscopy. The study excluded patients with any previous anti-H. pylori treatment, gastric malignancy, conservative management of sealed PPU, and those with a diameter of perforation less than the diameter of endoscopic biopsy forceps. Blood samples were taken for H. pylori serology IgG (ELISA) test. The mucosal biopsy samples from both the groups were tested with a rapid urease test and modified Giemsa stain examination to detect $\mathrm{H}$. pylori.

\section{Results}

The prevalence of H. pylori infection were significantly less in patients with PPU than with PUD: by rapid urease: $12.5 \%$ vs. $31.2 \%$, p: 0.002 ; modified Giemsa stain: $10.4 \%$ vs. $31.2 \%$, p: 0.012 ; and IgG serology: $50 \%$ vs. $68.7 \%$, p: 0.012 , respectively. Alcohol and tobacco were significant risk factors (p: 0.002 vs. p: 0.002 respectively). However, nonsteroidal anti-inflammatory drugs (NSAIDs) use was not a significant risk factor for PPU (p: 0.083).

\section{Conclusion}

H. pylori infection was not significantly associated with PPU. Some other factors like alcohol intake and tobacco were also involved in perforation. We can conclude that $\mathrm{H}$. pylori infection is not a risk factor for PPU.

Categories: Gastroenterology, General Surgery, Infectious Disease
Keywords: helicobacter pylori, peptic ulcer, smoking, nsaid, alcohol

\section{Introduction}

The incidence of perforated peptic ulcer (PPU) has only declined minimally despite the widespread use of Helicobacter pylori (H. pylori) eradicative agents. About $95 \%$ of the patients suffering from duodenal ulcers and $70-80 \%$ of the gastric ulcer patients are found to be $\mathrm{H}$. pylori-positive [1]. Although the role of $\mathrm{H}$. pylori is well known in peptic ulcer disease (PUD) etiology, its role in PPU is not well established [2-5]. There are conflicting results in the literature regarding its association. While some studies show a high prevalence of H. pylori infection in PPU patients, and its eradication preventing the relapse of ulcer, others show a low or complete lack of association, suggesting different pathogenesis for PPU [1,6-7]. Because of these conflicting results and paucity of data, this study was undertaken to assess the role of $\mathrm{H}$. pylori in patients with PPU.

\section{Materials And Methods}

This study aimed to assess the role of H. pylori infection in patients with PPU and to compare it with its prevalence in patients with PUD. This was a prospective analytical study conducted at a tertiary care center in South India for 17 months. Study patients were divided into two groups. Group I included patients above 18 years of age who were operated for gastro-duodenal perforation. Group II consisted of patients above 18 years of age with the upper gastrointestinal endoscopic diagnosis of PUD (peptic ulcer or erosive mucosal disease). 


\section{Cureus}

In the first group, the mucosal biopsy was taken during surgery from the antrum of the stomach through the perforation using sterile endoscopic biopsy forceps. In group 1l, after the endoscopic diagnosis of PUD, the mucosal biopsy was taken from the antrum of the stomach. The study excluded patients with any previous anti-H. pylori treatment, gastric malignancy, conservative management of sealed peptic perforation, and those with a diameter of perforation less than the diameter of endoscopic biopsy forceps. The biopsy samples from both the groups were subjected to rapid urease test and histopathological (modified Giemsa stain) examination to detect $\mathrm{H}$. pylori. The patients were considered to have $\mathrm{H}$. pylori infection if any one or both of the above tests were positive. Smokers were defined as patients who were smoking during the study and had smoked more than 100 cigarettes in the past year. Drinkers were defined as patients who had consumed alcohol in the past 12 months. Nonsteroidal anti-inflammatory drugs (NSAIDs) intake was defined as the current intake of NSAIDs in patients irrespective of the dosage.

\section{Statistical analysis}

The results of the primary outcome variables (H. pylori-positive PPU and PUD) and sociodemographic and clinical variables (age group, gender) were presented as absolute numbers and percentages. The difference between the two groups, with and without $\mathrm{H}$. pylori infection, was assessed using the Chi-square test, and a p-value of $<0.05$ was considered statistically significant.

\section{Results}

A total of 96 patients (48 patients in each group) was included in the study. The male-to-female ratio between the study groups was 15:1 and 3.8:1 respectively. The mean age of presentation was comparable between the groups ( $46.5 \pm 16$ years vs. $47.3 \pm 13$ years). The highest incidence of PPU was found in patients of 31-40 years age in group 1 and those of 51-60 years age in group II. Among them, 22 (45.8\%) patients were smokers, 27 (56.3\%) patients had a history of alcohol consumption, and 26 (54.2\%) patients had a history of NSAIDs use (Table 1).

\begin{tabular}{|c|c|c|c|}
\hline Parameter & Group I (n = 48) & Group II (n = 48) & P-value \\
\hline Age in years, mean $\pm S D$ & $46.5 \pm 2$ & $47.3 \pm 2$ & - \\
\hline Sex ratio (male-to-female) & $15: 1$ & 3.8:1 & - \\
\hline Smoking, n (\%) & $22(45.8)$ & $8(16.7)$ & 0.002 \\
\hline Alcohol intake, n (\%) & 27 (56.3) & $12(25)$ & 0.002 \\
\hline NSAIDs intake, n (\%) & $26(54.2)$ & $24(50)$ & 0.68 \\
\hline
\end{tabular}

\section{TABLE 1: Baseline parameters of the study groups}

NSAIDs: nonsteroidal anti-inflammatory drugs; SD: standard deviation

A significant statistical difference existed between group I and group II when alcohol intake and smoking were considered as positive risk factors (p: 0.002), as laid out in Table 2.

\begin{tabular}{|c|c|c|}
\hline Risk factors & Group I (\%) & Group II (\%) \\
\hline Alcoholic intake & 56.25 & 14.3 \\
\hline Smoking & 45.83 & 16.67 \\
\hline NSAIDs intake & 54.17 & 50 \\
\hline
\end{tabular}

TABLE 2: Distribution of risk factors between the study groups

NSAIDs: nonsteroidal anti-inflammatory drugs

Out of the 48 patients in group I, 42 (87.5\%) patients had pre-pyloric perforation, and six patients (12.5\%) had a perforation in the first part of the duodenum. Out of the 48 patients in group 11, 14 patients had antral gastritis, 14 patients had duodenitis, 17 patients had pan gastritis, and three patients had pre-pyloric ulcers (Table 3). 
In the present study, $45.8 \%$ of patients in group I were smokers, among which $13.63 \%$ tested positive for $\mathrm{H}$. pylori. In group II, only $16.66 \%$ were smokers of which only one patient was tested positive for H. pylori infection. Alcohol intake is another attributable risk factor for PPU. In the present study, 56.3\% of PPU patients had a history of alcohol intake and among them, two were tested positive for $\mathrm{H}$. pylori. In PUD patients, $25 \%$ had a history of alcohol consumption of which five were found to be positive for $\mathrm{H}$. pylori. The results were statistically significant (p: 0.002) when alcohol intake and smoking were considered as risk factors for PPU. Based on the OR (3.85 and 4.23, respectively), it was found that both alcohol intake and smoking were risk factors for PPU. This was similar to a study done by Ugochukwu et al., which showed that smoking and alcohol consumption were significantly associated with perforation in young men from developing countries [8]. Previous studies that show a significant association between H. pylori infection and PPU are listed below (Table 5) [8-10,12].

\begin{tabular}{|c|c|c|c|}
\hline Study & Year & Prevalence of $\mathrm{H}$. pylori infection in PPU, \% & Association \\
\hline Ugochukwu et al. [8] & 2013 & $65-70$ & Significant \\
\hline Dogra et al. $[9]$ & 2014 & 92 & Signiticant \\
\hline John B et al. [10] & 2017 & 47 & Signiticant \\
\hline Sebastian et al. [12] & 2001 & 83.3 & Significant \\
\hline
\end{tabular}

TABLE 5: Previous studies showing significant association between $\mathrm{H}$. pylori infection and PPU

H. pylori: Helicobacter pylori; PPU: perforated peptic ulcer

\section{Conclusions}

We found that alcohol intake and smoking were significant risk factors associated with perforation of gastroduodenal ulcers, whereas NSAIDs use was not significantly associated. H. pylori infection was not significantly associated with PPU, implying that some other factors were also involved in perforation.

\section{Additional Information}

\section{Disclosures}

Human subjects: Consent was obtained by all participants in this study. Institute Ethics Committee (Human studies) Reg no: ECR/342/Inst/PY/ 2013 issued approval JIP/IEC/2016/27/889. The Institute Ethics Committee of Jawaharlal Institute of Postgraduate Medical Education and Research, Puducherry has approved this study with approval no. JIP/IEC/2016/27/889. Animal subjects: All authors have confirmed that this study did not involve animal subjects or tissue. Conflicts of interest: In compliance with the ICMJE uniform disclosure form, all authors declare the following: Payment/services info: All authors have declared that no financial support was received from any organization for the submitted work. Financial relationships: All authors have declared that they have no financial relationships at present or within the previous three years with any organizations that might have an interest in the submitted work. Other relationships: All authors have declared that there are no other relationships or activities that could appear to have influenced the submitted work.

\section{References}

1. Peitz U, Leodolter A, Wex T, et al.: Diagnostics of Helicobacter pylori infection in patients with peptic ulcer bleeding. Z Gastroenterol. 2004, 42:141-146. 10.1055/s-2004-812836

2. Gisbert JP, Pajares JM: Helicobacter pylori and bleeding peptic ulcer: what is the prevalence of the infection in patients with this complication?. Scand J Gastroenterol. 2003, 38:2-9. 10.1080/00365521.2003.11800649

3. Ng EK, Lam YH, Sung IJ, et al.: Eradication of Helicobacter pylori prevents recurrence of ulcer after simple closure of duodenal ulcer perforation: randomized controlled trial. Ann Surg. 2000, 231:153-158. 10.1097/00000658-200002000-00001

4. Chu KM, Kwok KF, Law SY, Tuen HH, Tung PH, Branicki FJ, Wong J: Helicobacter pylori status and endoscopy follow-up of patients having a history of perforated duodenal ulcer. Gastrointest Endosc. 1999, 50:58-62. 10.1016/s0016-5107(99)70345-7

5. El-Nakeeb A, Fikry A, Abd El-Hamed TM, et al.: Effect of Helicobacter pylori eradication on ulcer recurrence after simple closure of perforated duodenal ulcer. Int J Surg. 2009, 7:126-129. 10.1016/j.ijsu.2008.12.001

6. Reinbach DH, Cruickshank G, McColl KE: Acute perforated duodenal ulcer is not associated with Helicobacter pylori infection. Gut. 1993, 34:1344-1347. 10.1136/gut.34.10.1344

7. Hobsley M, Tovey FI, Holton J: Precise role of H pylori in duodenal ulceration . World J Gastroenterol. 2006, 12:6413-6419. 10.3748/wig.v12.i40.6413

8. Ugochukwu AI, Amu OC, Nzegwu MA, Dilibe UC: Acute perforated peptic ulcer: on clinical experience in an urban tertiary hospital in south east Nigeria. Int J Surg. 2013, 11:223-227. 10.1016/j.ijsu.2013.01.015 


\section{Cureus}

9. Dogra B, Panchabhai S, Rejinthal S, Kalyan S, Priyadarshi S, Kandari A: Helicobacter pylori in gastroduodenal perforation. Med J DY Patil Univ. 2014, 7:170-172. 10.4103/0975-2870.126331

10. John B, Mathew BP, Chandran VP: Prevalence of Helicobacter pylori in peptic ulcer perforation . Int Surg J. 2017, 4:3350-3353. 10.18203/2349-2902.isj20174494

11. Gisbert JP, Legido J, García-Sanz I, Pajares JM: Helicobacter pylori and perforated peptic ulcer: prevalence of the infection and role of non-steroidal anti-inflammatory drugs. Dis Liver Dis. 2004, 36:116-120. 10.1016/j.dld.2003.10.011

12. Sebastian M, Chandran VP, Elashaal YI, Sim AJ: Helicobacter pylori infection in perforated peptic ulcer disease. Br J Surg. 1995, 82:360-362. 10.1002/bjs.1800820325

13. Gisbert JP, Pajares JM: Helicobacter pylori infection and perforated peptic ulcer: prevalence of the infection and role of antimicrobial treatment. Helicobacter. 2003, 8:159-167. 10.1046/j.1523-5378.2003.00139.x 